\title{
EFEK MODEL PEMBELAJARAN INQUIRY TRAINING BERBANTUAN MIND MAP TERHADAP HASIL BELAJAR SISWA PADA MATERI SUHU DAN KALOR DI KELAS X SMA NEGERI I BESITANG T.A 2014/2015
}

\author{
Siti Aisyah dan Motlan \\ Jurusan Fisika FMIPA Universitas Negeri Medan \\ Jalan Willem Iskandar Pasar V Medan, Sumatera Utara \\ staisyah@gmail.com
}

\begin{abstract}
ABSTRAK
Penelitian ini bertujuan untuk mengetahui apakah hasil belajar dengan menggunakan model pembelajaran inquiry training lebih baik daripada pembelajaran konvensional pada materi suhu dan kalor di kelas X semester II di SMA Negeri I Besitang T.A. 2014/2015. Jenis penelitian ini adalah quasi experiment dengan two group pre test post test design. Populasi penelitian adalah seluruh siswa kelas $\mathrm{X}$ semester genap yang terdiri dari 5 kelas. Pengambilan sampel dilakukan dengan cara cluster random sampling. Sampel yang terpilih adalah kelas kelas X-1 sebagai kelas eksperimen dengan model pembelajaran Inquiry Training dan kelas X-2 sebagai kelas kontrol dengan pembelajaran konvensional. Instrumen yang digunakan untuk mengetahui hasil belajar siswa adalah tes hasil belajar.Statistik yang digunakan untuk pengujian hipotesis penelitan ini adalah uji t. Berdasarkan analisis data dan pembahasan hasil pengujian hipotesis, simpulan penelitian ini adalah: ada pengaruh yang signifikan penggunaan model pembelajaran Inquiry Training terhadap hasil belajar yang diperoleh siswa pada materi pokok Suhu dan Kalor di SMA Negeri I Besitang.
\end{abstract}

Kata Kunci : pembelajaran inquiry training, konvensional hasil belajar

\begin{abstract}
This study aims to determine whether the results of learning by using inquiry learning model training better than conventional learning at the temperature and heat the material in the second semester in class X SMA I Besitang TA 2014/2015. This research is a quasi experimental two-group pretest posttest. design. Population in the study were all students of class $X$ semester consisting of 5 classes. Sampling was done by cluster random sampling. The selected sample is a class $X-1$ as the experimental class learning model Inquiry Training and class $X-2$ as the control class with conventional learning models. The instrument used to determine student learning outcomes is belajar.Statistik test results are used to test the hypothesis of this research is the t test. Based on data analysis and discussion of the results of hypothesis testing, the conclusion of this research is: there is a significant effect of use of learning model Inquiry Training on learning outcomes of students who obtained the subject matter of Temperature and Heat in SMA I Besitang.
\end{abstract}

Keywords: inquiry learning training, conventional learning outcomes 


\section{PENDAHULUAN}

Masalah utama dalam pembelajaran pada pendidikan formal (sekolah) dewasa ini adalah masih rendahnya daya serap peserta didik. Hal ini tampak dari rerata hasil belajar peserta didik yang senantiasa masih sangat memperihatinkan. Berdasarkan dari hasil wawancara dengan salah seorang guru fisika di SMA Negeri 1 Besitang diperoleh metode yang digunakan oleh guru bidang studi fisika adalah ceramah, dan penugasan. Metode ceramah bila selalu digunakan dan terlalu lama akan menyebabkan kebosanan. Metode ini juga membuat guru mendominasi kegiatan belajar mengajar di dalam kelas sehingga siswa menjadi pasif. Dan pembelajaran yang digunakan dikelas masih cenderung berpusat pada guru (teacher-centered). Selain itu jika dilihat nilai fisika yang dicapai siswa rata- rata 55, masih jauh di bawah Kriteria Ketuntasan Minimum (KKM) yakni 75. Dari angket yang disebarkan kepada siswa SMA Negeri I Besitang, di antaranya sebanyak 50\% siswa-siswi mengatakan kegiatan belajar mengajar pada mata pelajaran fisika sulit dipahami dan membosankan, kemudian sebanyak 63, 33\% mengatakan nilai hasil belajar fisika tidak memuaskan, dan 73, $33 \%$ siswa mengatakan guru jarang menggunakan media sederhana ketika mengajar. Dari kesimpulan itu, memperlihatkan bahwa hasil belajar siswa untuk pelajaran fisika masih rendah. Rendahnya hasil belajar ini disebabkan adanya permasalahan dalam belajar.

Dari hasil wawancara dan angket di atas, maka diperlukan salah satu upaya untuk mengatasi permasalahan di atas yakni dengan mengembangkan model pembelajaran efektif, yang dapat menarik perhatian siswa, membangkitkan motivasi siswa, melibatkan siswa secara aktif, melatih kemampuan siswa, dan mengembangkan kemampuan berpikir kreatif siswa. Dimana pada saat ini banyak model yang dapat meningkatkan siswa menjadi aktif dan kreatif pada saat proses pembelajaran, misalnya adalah model pembelajaran inquiry training. Model pembelajaran inquiry training ini ditujukan untuk membangun mental kognitif. Karenanya sangat sesuai untuk untuk mengembangkan kemampuan berpikir, kemudian model ini secara tidak langsung dapat mengembangkan kemampuan berpikir kreatif, karena model ini bertujuan untuk melatih kemampuan siswa dalam meneliti, menjelaskan fenomena dan memecahkan masalah secara ilmiah.

Berdasarkan masalah di atas, penulis berkeinginan melakukan suatu penelitian untuk mengetahui perbedaan hasil belajar siswa menggunakan model pembelajaran inquiry training dengan menggunakan media mind map dengan model pembelajaran konvensional.

\section{METODE PENELITIAN}

Penelitian ini dilaksanakan di SMA Negeri 1 Besitang yang beralamat dijalan RGM, kecamatan besiitang, kabupaten langkat dan pelaksanaannya pada semester II T.A. 2014/2015.

Berdasarkan tujuan penelitian, yang menjadi populasi dalam penelitian ini adalah siswa kelas $\mathrm{X}$ semester II T.A. 2014/2015 yang terdiri dari lima kelas yaitu dari kelas X-1 sampai X -5.

Sampel dalam penelitian ini terdiri dari dua kelas yaitu kelas X-2 sebagai kelas kontrol dan kelas $\mathrm{X}-1$ sebagai kelas eksperimen yang diambil dengan teknik cluster random sampling.

Jenis penelitian ini termasuk penelitian quasi eksperimen. Desain penelitian ini dapat dilihat pada Tabel 1.

Tabel 1. Two Group Pretes - Posttes

Design (Arikunto, 2012)

\begin{tabular}{|l|c|c|c|}
\hline \multicolumn{1}{|c|}{ Kelompok } & Pretes & Perlakuan & Postes \\
\hline $\begin{array}{l}\text { Kelas } \\
\text { eksperimen }\end{array}$ & $\mathrm{T}_{1}$ & $\mathrm{X}$ & $\mathrm{T}_{2}$ \\
\hline $\begin{array}{l}\text { Kelas } \\
\text { kontrol }\end{array}$ & $\mathrm{T}_{1}$ & $\mathrm{Y}$ & $\mathrm{T}_{2}$ \\
\hline
\end{tabular}

Keterangan :

$\mathrm{T}_{1}=$ Pretes diberikan kepada kelas eksperimen dan kelas kontrol sebelum perlakuan 
$\mathrm{T}_{2}=$ Postes diberikan setelah perlakuan pada kelas eksperimen dan kelas kontrol

$\mathrm{X}=$ Pengajaran dengan menerapkan model pembelajaran Inquiry Training

$\mathrm{Y}=$ Pengajaran dengan menerapkan model pembelajaran konvensional

$\mathrm{T}_{1}=\mathrm{T}_{2}$ (soal pretes sama dengan soal postes)

Uji normalitas digunakan untuk melihat apakah sampel berdistribusi normal atau tidak. Pengujian ini dilakukan pada saat pengumpulan data tes awal (pretes) Uji yang digunakan adalah Lilliefors.

Pengujian hipotesis dilakukan dengan dua cara yaitu uji t satu pihak dan uji t dua pihak. Uji t dua pihak digunakan untuk mengetahui kesamaan kemampuan awal siswa pada kedua kelompok sampel.

Bila data penelitian berdistribusi normal dan homogen maka untuk menguji hipotesis menggunakan uji t dengan rumus (Sudjana, 2005), yaitu :

dimana $\mathrm{S}$ adalah varians gabungan yang dihitung dengan rumus :

$$
\begin{aligned}
& =\text { Varians kelas kontrol } \\
& =\text { Varians dua kelas } \\
& \text { sampel }
\end{aligned}
$$

Kriteria pengujian adalah : terima $\mathrm{H}_{\mathrm{O}}$ jika dimana didapat dari daftar distribusi $t$ dengan $\mathrm{dk}=\mathrm{n}_{1}+\mathrm{n}_{2}-2$ dan . Untuk harga $\mathrm{t}$ lainnya $\mathrm{H}_{\mathrm{O}}$ ditolak.

Jika pengolahan data menunjukkan bahwa, atau nilai t hitung yang diperoleh berada diantara dan, maka $\mathrm{H}_{0}$ diterima. Dapat diambil kesimpulan bahwa kemampuan awal siswa pada kelas eksperimen sama dengan kemampuan awal siswa pada kelas kontrol. Jika pengolahan data menunjukkan nilai $\mathrm{t}$ hitung tidak berada diantara dan, $\mathrm{H}_{0}$ ditolak dan terima $\mathrm{H}_{\mathrm{a}}$, dapat dimabil kesimpulan bahwa kemampuan awal siswa pada kelas eksperimentidak sama dengan kemampuan awal siswa pada kelas kontrol. Kriteria pengujiannya adalah : Terima $\mathrm{H}_{0}$, jika dimana didapat dari daftar distribusi $\mathrm{t}$ dengan peluang (1-) dan $\mathrm{dk}=$ $\mathrm{n}_{1}+\mathrm{n}_{2}-2$ dan . Untuk harga $\mathrm{t}$ yang lain $\mathrm{H}_{\mathrm{O}}$ ditolak.

Jika pengolahan data menunjukkan bahwa, atau nilai t hitung yang diperoleh lebih dari nilai , maka hipotesis $\mathrm{H}_{0}$ ditolak dan terima $\mathrm{H}_{\mathrm{a}}$. Dapat diambil kesimpulan hasil belajar fisika siswa pada kelas eksperimen(dengan menggunakan model pembelajaran inquiry training berbantuan mind map lebih besar dibandingkan hasil belajar siswa pada kelas kontrol (dengan menggunakan model pembelajaran konvensional), maka pembelajaran dengan model pembelajaran inquiry training berbantuan mind map dikatakan berpengaruh terhadap hasil belajar siswa.

\section{HASIL PENELITIAN DAN \\ PEMBAHASAN \\ Hasil Penelitian}

Tabel-tabel di bawah ini menjelaskan seluru hasil penelitian yang diperoleh melaui analisi data.

Tabel 2. Rata-rata nilai pretes dan postes kelas eksperimen dan kontol

\begin{tabular}{|c|c|c|c|c|c|}
\hline No & Jenis Perlakuan & \multicolumn{2}{|c|}{ Rata-rata } & \multicolumn{2}{c|}{ Standart Deviasi } \\
\hline & & Pretes & Postes & Pretes & Postes \\
\hline 1 & Kelas Eksperimen & 46,28 & 68,95 & 8,70 & 12,53 \\
\hline 2 & Kelas Kontrol & 47,26 & 58,29 & 8.76 & 9.48 \\
\hline
\end{tabular}

Tabel 3. Ringkasan Hasil Uji Normalitas Kelas Eksperimen dan Kelas Kontrol

\begin{tabular}{|c|c|c|c|c|}
\hline No & Data Kelas & L & $\begin{array}{c}\mathrm{L}_{\text {tabel }} \\
\alpha=0,05 \\
\mathrm{n}=35\end{array}$ & Kesimpulan \\
\hline 1 & Pre-tes Ekperimen & 0,1411 & 0.1498 & Berdistribusi Normal \\
\hline 2 & Pos-tes Ekperimen & 0,1326 & & Berdistribusi Normal \\
\hline
\end{tabular}




\begin{tabular}{|l|l|l|l|l|}
\hline 3 & Pre-tes Kontrol & 0,1239 & & Berdistribusi Normal \\
\hline 4 & Pos-tes Kontrol & 0,1429 & & Berdistribusi Normal \\
\cline { 2 - 3 }
\end{tabular}

Tabel 4. Ringkasan Hasil Uji Homogenitas Kedua Kelas

\begin{tabular}{|c|c|c|c|c|c|}
\hline No & Data Kelas & Varians & $\mathrm{F}_{\text {hitung }}$ & $\mathrm{F}_{\text {tabel }}$ & Kesimpulan \\
\hline 1 & Pretes eksperimen & 75.67 & \multirow{2}{*}{1.01} & 1,80 & \multirow{2}{*}{ Homogen } \\
\hline 2 & Pretes kontrol & 76.79 & & & \multirow{2}{*}{ Homogen } \\
\hline 3 & Postes ekperimen & 152.04 & \multirow{2}{*}{1,69} & \multirow{2}{*}{1,80} & \\
\hline 4 & Postes kontrol & 89.79 & &
\end{tabular}

Tabel 5. Ringkasan Perhitungan Uji Hipotesis Kemampuan Awal / Pretes Siswa

\begin{tabular}{|c|c|c|c|c|c|}
\hline No & Data Kelas & Nilai Rata-Rata & $\mathrm{t}_{\text {hitung }}$ & $\mathrm{t}_{\text {tabel }}$ & Kesimpulan \\
\hline 1 & Eksperimen & 46,28 & \multirow{2}{*}{-0.46} & 1,99 & \multirow{2}{*}{ Kemampuan Awal Sama } \\
\hline 2 & Kontrol & 47.26 & & \\
\hline
\end{tabular}

Tabel 6. Ringkasan Perhitungan Uji Hipotesis Postes Siswa

\begin{tabular}{|c|c|c|c|c|l|}
\hline No & Data Kelas & $\begin{array}{c}\text { Nila Rata- } \\
\text { Rata }\end{array}$ & $\mathrm{t}_{\text {hitung }}$ & $\mathrm{t}_{\text {tabel }}$ & \multicolumn{1}{|c|}{ Kesimpulan } \\
\hline 1 & Eksperimen & 68.95 & \multirow{2}{*}{4.06} & 1,67 & $\begin{array}{l}\text { Hasil belajar kelas eksprimen lebih } \\
\text { baik daripada kelas kontrol }\end{array}$ \\
\hline 2 & Kontrol & 58.29 & 4.96 &
\end{tabular}

Gambar 1. Grafik pretes postes dan aktivitas siswa

Pada tahapan penelitian, kedua Besitang Kabupaten Langkat kelas sampel yaitu kelas eksperimen dan kelas kontrol diberikan pretes sebagai syarat awal penelitian yang bertujuan untuk melihat kemampuan awal belajar siswa pada kedua kelas tersebut.

Hasil dari penelitian ini adalah bahwa nilai rata-rata pretes kelas ekspreimen sebesar 46.28 dan nilai rata-rata pretes kelas kontrol sebesar 47.26

Kelas eksperimen diberikan pembelajaran dengan model Inquiry Training dan pada kelas kontrol diberikan pembelajaran konvensional setelah diberi perlakuan yang berbeda, diperoleh bahwa rata-rata postes kelas eksperimen 68.95 dan rata-rata postes kelas kontrol 58.29.

Perhitungan uji perbedaan nilai ratarata postes kelas ekperimen dan kelas kontrol, diperoleh $t_{\text {hitung }}=4.06>1,67$, maka $\mathrm{H}_{0}$ ditolak dan $\mathrm{H}_{\mathrm{a}}$ diterima. Sehingga diperoleh kesimpulan bahwa model pembelajaran inquiry training memiliki efek yang lebih baik daripada pembelajaran konvensional pada materi pokok suhu dan kalor dikelas $\mathrm{X}$ semester I SMAN 1 T.P.2014/2015.

\section{Pembahasan}

Grafik pada gambar 1 diperoleh dengan menggunakan program Microsoft Office Excel 2007. Persamaan linear $y=a x$ $+b$ memiliki nilai yang menyatakan kemiringan garis. Jika terlihat dari grafik, nilai $a$ pada $y_{\text {post }}=0,052 x+77.44$ lebih tingi dibandingkan dengan nilai a pada $y_{\text {pre }}$ $=0,035 x+45.78$. Maka berpengaruh terhadap terhadap hasil belajar siswa.

Dalam penelitian ini pembagian kelompok sudah dapat dikatakan berhasil karena terbukti bahwa aktivitas setiap siswa pada kelompok mempengaruhi peningkatan nilai postes. Agar aktivitas kelompok lebih berpengaruh terhadap hasil belajar disarankan agar membuat perencanaan yang lebih baik pada pengorganisasian kelompok.

Beberapa penelitian yang relevan dengan penelitian ini seperti dalam Harahap dan Sinuraya (2014) mengenai model pembelajaran inquiry training dapat 
meningkatkan hasil belajar siswa, dimana diperoleh nilai rata-rata pretes di kelas eksperimen dan kelas kontrol adalah 34,875 dan 33,5. Setelah diberi perlakuan, diperoleh rata-rata nilai postes pada kelas eksperimen dan kelas kontrol adalah 70,375 dan 63,125. Begitu juga dengan aktivitas dengan menerapkan model pembelajaran inquiry training, dimana terdapat peningkatan aktivitas yaitu 51,33 pada pertemuan I dan 70,33 pada pertemuan kedua. Maka disimpulkan bahwa ada pengaruh yang signifikan model pembelajaran inquiry training terhadap hasil belajar siswa. Begitu juga pada penelitian Hayati dan Dwi, (2013), diperoleh nilai raa-rata pretes 4,29 dan nilai rata-rata postes 6,29 untuk kelas eksperimen dan nilai rata-rata pretes 4,03 dan nilai rata-rata postes 5,64 untuk kelas kontrol. Dapat dilihat bahwa peningkatan hasil belajar lebih tinggi dikelas eksperimen yaitu dengan penerapan model pembelajaran inquiry training. Demikian juga dengan rata-rata aktivitas yang diperoleh yaitu sebesar 67,38 dengan kategori aktif.

\section{KESIMPULAN}

Berdasarkan hasil penelitian yang diperoleh dari hasil analisis data dan pengujian hopotesis maka dapat disimpulkan:

1. Pembelajaran dengan model Inquiry Training sebelum diberikan perlakuan rata-rata pretes sebesar 46,28 dan setelah diberikan perlakuan rata-rata postes siswa sebesar 68,95 .

2. Pembelajaran secara konvensional sebelum diberikan perlakuan rata-rata pretes sebesar 47,26 dan setelah diberikan perlakuan rata-rata postes siswa sebesar 58,29.

3. Dari hasil uji hipotesis didapat hasilnya signifikan, sehingga hasil belajar siswa dengan menerapkan model pembelajaran Inquiry Training memiliki efek yang lebih baik dibandingkan dengan pembelajaran konvensional.

\section{DAFTAR PUSTAKA}

Arikunto, S., (2012), Dasar-dasar Evaluasi Pendidikan, Jakarta: Bumi Aksara

Harahap, F. dan Sinuraya, J. 2013. Pengaruh Model Pembelajaran Inquiry Training terhadap Hasil Belajar Siswa pada Materi Pokok Suhu dan Pengukuran Kelas VII Semester I MTs N 2 Medan. Jurnal INPAFI.

Hayati dan Dwi, R. S. 2013. Efek Model Pembelajaran Inquiry Training Berbasis Multimedia dan Motivasi terhadap Hasil Belajar Fisika Siswa. Jurnal Online Pendidikan Fisika.

Sudjana, N., (2005), Metode Statistik, Bandung: Tarsito. 